\title{
Correlation between disease activity and serum ferritin in clinically amyopathic dermatomyositis with rapidly-progressive interstitial lung disease: a case report
}

Kazuhiro Yamada ${ }^{1}$, Kazuhisa Asai ${ }^{*}$, Atsuko Okamoto ${ }^{1}$, Tetsuya Watanabe ${ }^{1}$, Hiroshi Kanazawa' , Mai Ohata², Masahiko Ohsawa ${ }^{2}$ and Kazuto Hirata'

\begin{abstract}
Background: Clinically amyopathic dermatomyositis with anti-Melanoma Differentiation-Associated gene 5 (MDA5) antibody often presents with severe interstitial lung disease. Although serum ferritin level is known to reflect interstitial lung disease activity, there are few case reports describing this association.

Case presentation: A 58-year-old man was referred to our outpatient clinic with a 3-week history of cough and respiratory distress. He had erythema over the $V$ area of the neck and a Gottron's sign. Chest computed tomography revealed diffuse ground-glass opacities and reticular shadows in both lungs. Test for anti-MDA5 antibody was positive. After admission, he received triple combination therapy (methylprednisolone pulse therapy, tacrolimus, and cyclophosphamide). However, his respiratory condition worsened as the serum ferritin level increased. Despite no apparent deterioration on chest radiography, he ultimately died due to respiratory failure.

Conclusions: In this case, triple combination therapy was not effective for the patient's respiratory condition. The serum ferritin level was correlated with disease activity and was more useful than chest radiography for monitoring clinical status.
\end{abstract}

Keywords: Clinically amyopathic dermatomyositis, CADM, Rapidly progressive interstitial lung disease, RP-ILD, Melanoma Differentiation-Associated gene 5, MDA5, Corticosteroids, Tacrolimus, Cyclophosphamide

\section{Background}

Patients with clinically amyopathic dermatomyositis (CADM) with anti-Melanoma Differentiation-Associated gene 5 (MDA5) antibody often develop treatment-resistant, and rapidly-progressive interstitial lung disease (RPILD) [1]. In CADM-ILD, $80 \%$ of fatal cases died due to refractory ILD within 90 days of initial presentation [2]. Early treatment of CADM with RP-ILD is essential to improve the prognosis $[3,4]$. Triple combination therapy (corticosteroids, tacrolimus, and cyclophosphamide) is considered effective for CADM with RP-ILD. Although

\footnotetext{
*Correspondence: kazuasai@med.osaka-cu.ac.jp

${ }^{1}$ Department of Respiratory Medicine, Graduate School of Medicine, Osaka

City University, 1-4-3, Asahi-machi, Abeno-ku, Osaka 545-8585, Japan

Full list of author information is available at the end of the article
}

the serum ferritin level is known to predict prognosis in anti-MDA5 antibody-associated ILD with dermatomyositis and is also known to reflect disease activity, few case reports have described this association. We report a case in which the serum ferritin level was closely correlated with disease activity.

\section{Case presentation}

A 58-year-old man was referred to our outpatient clinic with a 3-week history of cough and respiratory distress. He was a current smoker (40 pack-years) but had no other medical history. His body temperature was $37.2^{\circ} \mathrm{C}$, blood pressure was $82 / 51 \mathrm{mmHg}$, pulse rate was 110 beats $/ \mathrm{min}$, respiratory rate was 20 breaths/min, and oxygen saturation was $84 \%$ in room air. He had erythema over the $\mathrm{V}$ 
area of the neck and a Gottron's sign (Fig. 1a), but no signs of muscle weakness. Fine crackles were auscultated in the bilateral lung bases. The serum level of creatine kinase was not elevated $(68.0 \mathrm{U} / \mathrm{L})$. The serum aldolase, Krebs von den Lungen-6, lactate dehydrogenase, and ferritin levels were increased (11.0, 1.040, $658 \mathrm{U} / \mathrm{L}$ and $1.679 \mathrm{ng} / \mathrm{mL}$, respectively). Anti-aminoacyl tRNA synthetase and other antibodies suggestive of autoimmune disorders were not detected (Table 1). Chest radiography showed bilateral reticular shadows, predominantly in the right lung (Fig. 1b). Chest computed tomography (CT) showed bilateral, asymmetric, ground-glass opacities and reticular shadows, predominantly in the lower lungs, suspicious for CADM with RP-ILD (Fig. 1c). Bronchoalveolar lavage was performed from right B5. The total cell count was $0.394 \times 10^{5} / \mathrm{mL}$, and the percentages of neutrophils, eosinophils, and lymphocytes were 47.2, 1.8 , and $21.6 \%$, respectively. A transbronchial lung biopsy specimen from right $\mathrm{B} 2 \mathrm{~b}$ showed a diffuse alveolar damage pattern (Fig. 2a). Following bronchoscopy, methylprednisolone pulse therapy (1000 mg daily for 3 days) and tacrolimus were initiated, followed by cyclophosphamide pulse therapy (500 $\mathrm{mg}$ for 1 day). After starting treatment, test for anti-MDA5 antibody was confirmed to be positive. Therefore, the diagnosis was CADM with antiMDA5 antibody. His respiratory condition gradually improved, and the serum ferritin, lactate dehydrogenase, and aldolase levels decreased. However, after 4 weeks, his respiratory condition gradually worsened in association with an increasing serum ferritin level, but there was no deterioration on chest radiography (Figs. 3, 4). Although courses of methylprednisolone and cyclophosphamide pulse therapy were repeated, his respiratory condition worsened, and he died on hospital day 43. An autopsy showed diffuse fibrosis in all three right lung lobes. Some lymphocytic infiltrate was present in the alveolar wall. Diffuse fibrosis was present and local organizing pneumonia was observed in the left lung (Fig. 2b).

\section{Discussion and conclusion}

Reportedly increasing in the past decade, CADM-ILD is often refractory and rapidly progressive, and CADMILD with anti-MDA 5 antibody has a poor prognosis. For early initiation of proper treatment, quick and accurate a
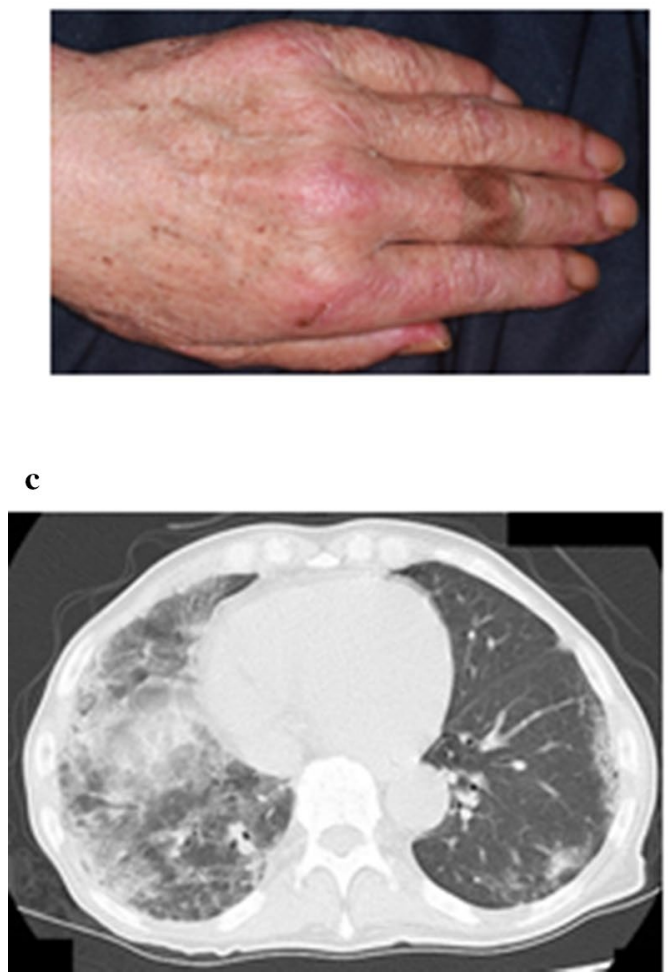

b
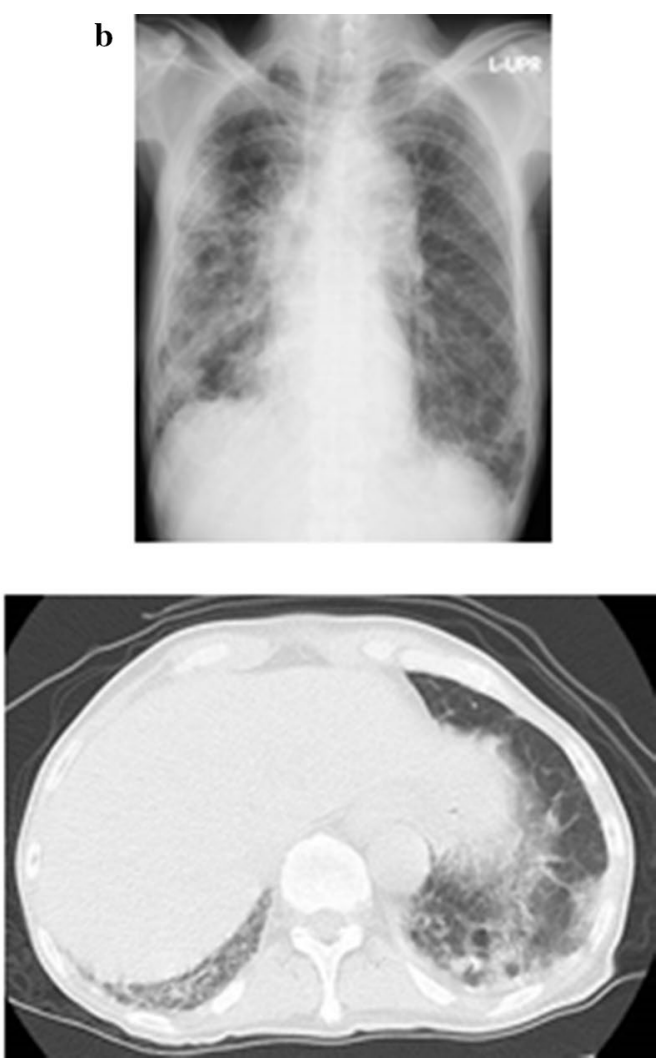

Fig. 1 a The clinical presentation on admission. Papules were observed near the interphalangeal articulations (Gottron's sign). b Chest radiography showed bilateral reticular shadows, in the right lung. c Chest CT scan showed bilateral, asymmetric, ground-glass opacities and reticular shadows, predominantly in the lower lung 
Table 1 Laboratory data

\begin{tabular}{|c|c|c|c|}
\hline Hematology & & Serology & \\
\hline $\mathrm{RBC}$ & $467 \times 10^{4} / \mu \mathrm{L}$ & CRP & $3.28 \mathrm{mg} / \mathrm{dL}$ \\
\hline $\mathrm{Hb}$ & $13.4 \mathrm{~g} / \mathrm{dL}$ & $\lg G$ & $1742 \mathrm{mg} / \mathrm{dL}$ \\
\hline $\mathrm{Ht}$ & $40.7 \%$ & $\lg A$ & 443 mg/dL \\
\hline WBC & $9400 / \mu \mathrm{L}$ & $\lg M$ & $68 \mathrm{mg} / \mathrm{dL}$ \\
\hline Neutro & $76 \%$ & $\mathrm{KL}-6$ & $1040 \mathrm{U} / \mathrm{mL}$ \\
\hline Lymph & $14 \%$ & Immunological test & \\
\hline Mono & $4 \%$ & RF & $<5 \mathrm{U} / \mathrm{mL}$ \\
\hline Eosino & $5 \%$ & Anti nuclear Ab & 40-fold \\
\hline Plt & $37.8 \times 10^{4} / \mu \mathrm{L}$ & Anti CCP Ab & $<0.6 \mathrm{U} / \mathrm{mL}$ \\
\hline Blood chemistry & & Anti Ds-DNA Ab & $2.9 \mathrm{U} / \mathrm{mL}$ \\
\hline $\mathrm{TP}$ & $7.0 \mathrm{~g} / \mathrm{dL}$ & Anti RNP Ab & Negative \\
\hline Alb & $2.7 \mathrm{~g} / \mathrm{dL}$ & Anti SS-A Ab & $<1.0 \mathrm{U} / \mathrm{mL}$ \\
\hline T-bil & $0.5 \mathrm{mg} / \mathrm{dL}$ & Anti SS-B Ab & $<1.0 \mathrm{U} / \mathrm{mL}$ \\
\hline AST & $72 \mathrm{U} / \mathrm{L}$ & Anti SCl-70 & $<1.0 \mathrm{U} / \mathrm{mL}$ \\
\hline ALT & $27 \mathrm{U} / \mathrm{L}$ & PR3-ANCA & $<1.0 \mathrm{U} / \mathrm{mL}$ \\
\hline LDH & $658 \mathrm{U} / \mathrm{L}$ & MPO-ANCA & $<1.0 \mathrm{U} / \mathrm{mL}$ \\
\hline CK & $68 \mathrm{U} / \mathrm{L}$ & Anti ARS Ab & $<5.0 \mathrm{U} / \mathrm{mL}$ \\
\hline BUN & $21 \mathrm{mg} / \mathrm{dL}$ & \multicolumn{2}{|c|}{$\begin{array}{l}\text { Blood gas }\left(\mathrm{O}_{2} 3 \mathrm{~L} / \mathrm{min} \text { by nasal }\right. \\
\text { plugs })\end{array}$} \\
\hline \multirow[t]{6}{*}{ Cre } & $0.65 \mathrm{mg} / \mathrm{dL}$ & $\mathrm{PH}$ & 7.444 \\
\hline & & $\mathrm{PaCO}_{2}$ & 36 Torr \\
\hline & & $\mathrm{PaO}_{2}$ & 72 Torr \\
\hline & & $\mathrm{HCO}_{3}^{-}$ & $24.3 \mathrm{mEq} / \mathrm{L}$ \\
\hline & & B.E. & $1.0 \mathrm{mEq} / \mathrm{L}$ \\
\hline & & $\mathrm{SaO}_{2}$ & $94 \%$ \\
\hline
\end{tabular}

diagnosis is needed. This case showed a Gottron's and V-neck signs; however, muscle weakness was not apparent. Chest CT showed bilateral, asymmetric, groundglass opacities and reticular shadows, in the lower lungs, suspicious for CADM-ILD. Testing for anti-MDA5 antibody was positive. For initiation of proper treatment, accurate estimation of prognosis is needed. Gono et al. reported that elevated serum ferritin levels were related to the severity of ILD in patients with dermatomyositis. Interestingly, they found that the cumulative survival rate was lower in the subset with ferritin $\geq 1500 \mathrm{ng} / \mathrm{mL}$ than in the subset with ferritin $<1500 \mathrm{ng} / \mathrm{mL}$ [5]. Ferritin is the primary iron storage molecule; it is secreted by activated macrophages and plays a crucial role in sequestration of potentially harmful reactive iron molecules. High serum ferritin level may reflect aberrant activation of macrophages in patients with CADM-ILD. In this case, the serum ferritin level was $1679 \mathrm{ng} / \mathrm{mL}$ on the day of admission. A transbronchial lung biopsy specimen from right $\mathrm{B} 2 \mathrm{~b}$ showed proliferative phase diffuse alveolar damage (DAD). DAD is reportedly associated with a poorer prognosis than other histopathological patterns, such as unusual interstitial pneumonia [6].

Based both on the serum ferritin level and pathological findings, we predicted a poor prognosis and immediately initiated intensive treatment with triple combination therapy (corticosteroid, tacrolimus, and cyclophosphamide). T cells play a vital role in development of ILD in polymyositis/dermatomyositis [7, 8]; therefore, use of calcineurin inhibitors of T-cell activity is considered important. Cyclosporine inhibits the activity of calcineurin by binding to cyclophilin, whereas tacrolimus exhibits inhibitory activity by binding to FK binding protein. The pharmacological effect of tacrolimus is 100 times stronger than that of cyclosporine, and its half-life is longer than that of cyclosporine [9]. The superiority of tacrolimus to cyclosporine in renal, liver, or bone marrow transplantation has been demonstrated in randomized controlled trials [10-13]. Kameda et al. reported that 5 of 10 dermatomyositis patients with RP-ILD responded to triple combination therapy [14]. These reports indicate a

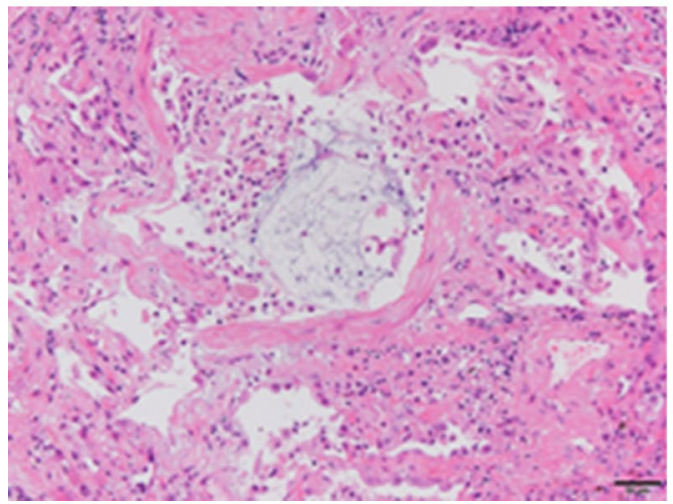

b

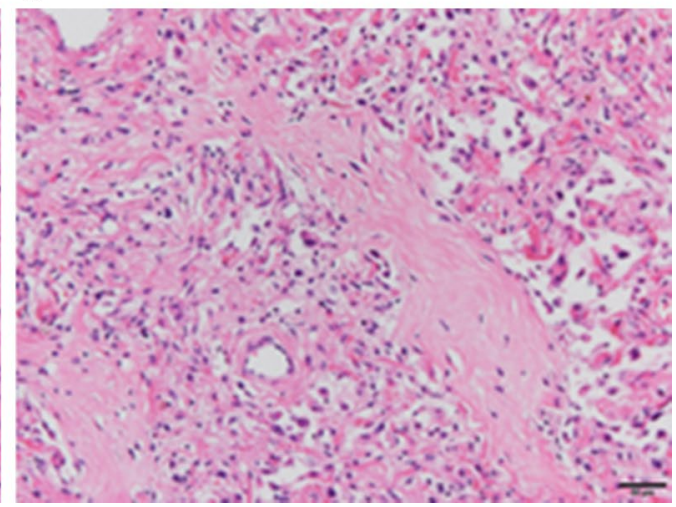

Fig. 2 a Transbronchial lung biopsy showed proliferative-phase diffuse alveolar damage with a glassy eosinophilic substance in the alveolar spaces and interstitial fibrosis associated with type 2 pneumocyte hyperplasia. b Autopsy lung section showed fibrotic-phase diffuse alveolar damage with diffuse fibrotic change and type 2 pneumocyte hyperplasia, with lymphocyte infiltration into alveolar septa 


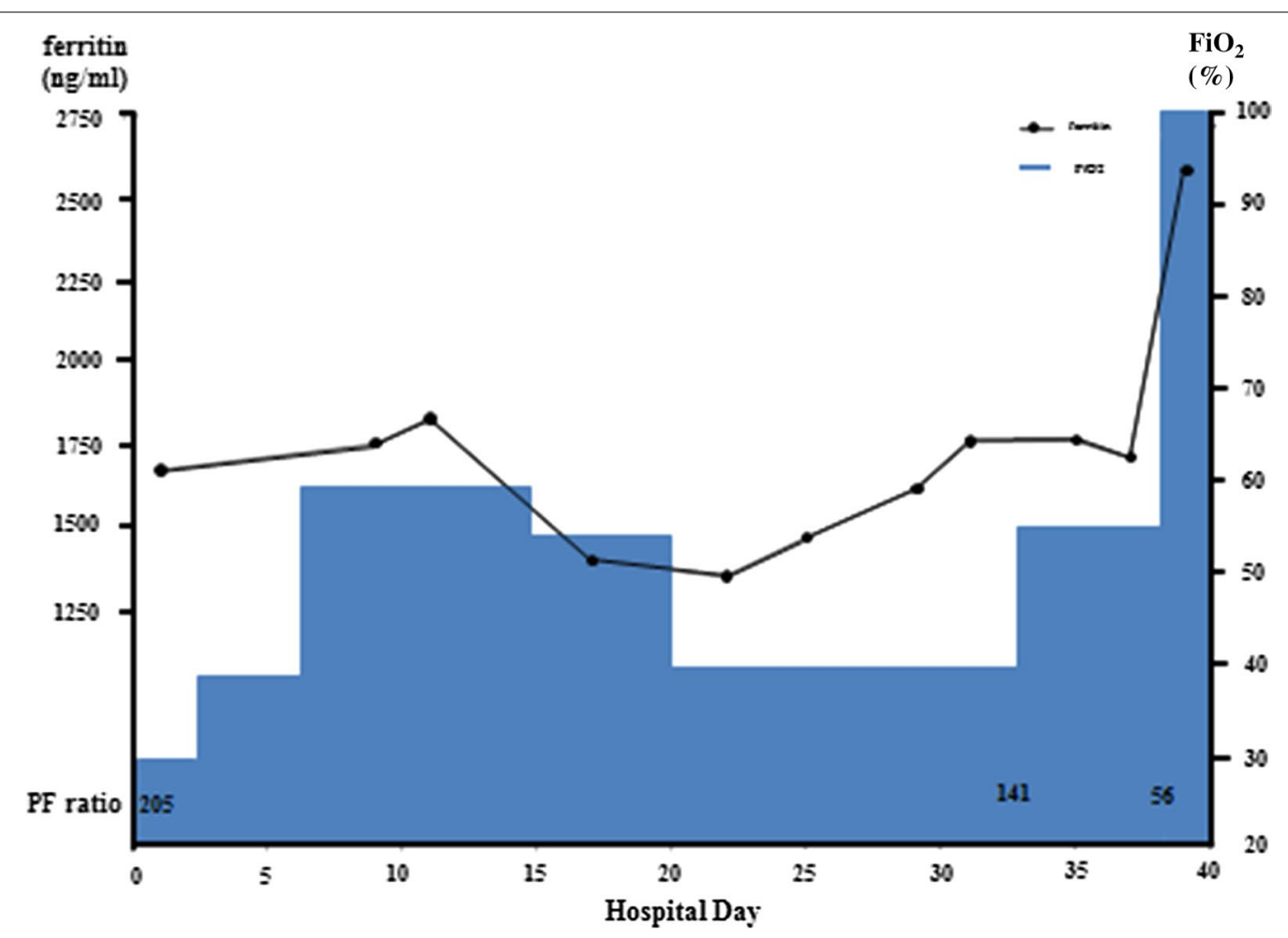

Fig. 3 The concentration of oxygen required changed in association with the serum ferritin level

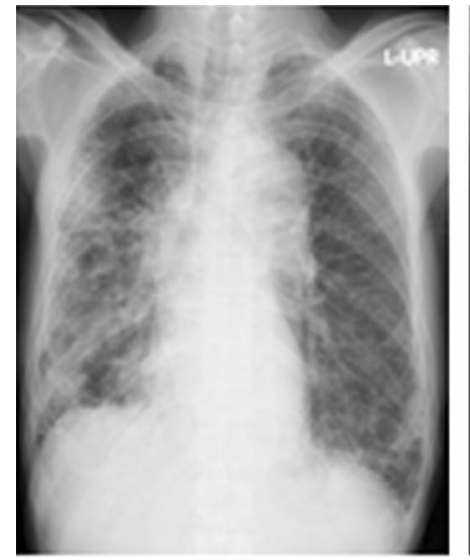

On admission

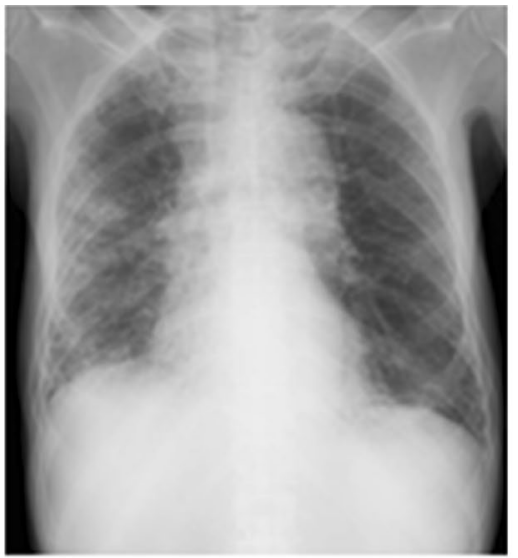

Day 29

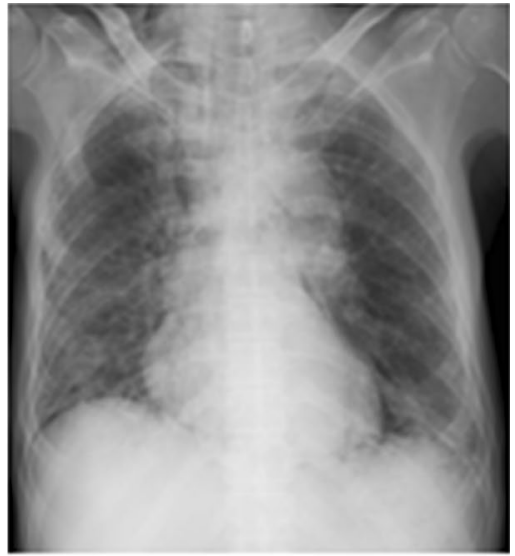

Day 38

Fig. 4 Chest radiography did not show apparent deterioration in association with the serum ferritin level

that triple combination therapy is warranted in cases of CADM with RP-ILD. Therefore, we administered cyclophosphamide from the beginning of treatment. Unfortunately, triple combination therapy was not effective. The patient's respiratory condition worsened without apparent deterioration on chest radiography. An adequate treatment-monitoring tool is needed to enable disease control.
The serum ferritin level is reportedly correlated with disease activity in anti-MDA5 antibody-associated ILD with dermatomyositis $[5,15]$ In this case, the treatment was initially effective; however, his respiratory condition worsened in association with an increasing serum ferritin level, and he died on hospital day 43. Lung specimens at autopsy showed fibrotic phase DAD. The serum ferritin level was closely correlated with disease activity 
(Fig. 3). There was no apparent deterioration of ILD on chest radiography (Fig. 4). This case indicated that a high serum ferritin level in anti-MDA5 antibody-associated ILD with dermatomyositis was very useful for monitoring disease activity. High serum ferritin level reflected disease activity in anti-MDA5 antibody-associated ILD with dermatomyositis. In this case, the serum ferritin level was more useful than chest radiography for monitoring of disease progression.

\section{Abbreviations}

CADM: clinically amyopathic dermatomyositis; MDA5: Melanoma Differentiation-Associated gene 5; RP-ILD: rapidly progressive interstitial lung disease; $C T$ : chest computed tomography; DAD: diffuse alveolar damage.

\section{Authors' contributions}

$\mathrm{KY}$ edited the case presentation, performed the literature review and wrote the discussion. AO, TW, KA, HK and $\mathrm{KH}$ revised the manuscript. $\mathrm{MO} 1$ and $\mathrm{MO} 2$ carried out the pathological diagnosis. All authors read and approved the final manuscript.

\section{Author details}

1 Department of Respiratory Medicine, Graduate School of Medicine, Osaka City University, 1-4-3, Asahi-machi, Abeno-ku, Osaka 545-8585, Japan. ${ }^{2}$ Diagnostic Pathology, Graduate School of Medicine, Osaka City University, 1-4-3, Asahi-machi, Abeno-ku, Osaka 545-8585, Japan.

\section{Acknowledgements}

We thank to Ms. Sachi Ibuki in Kyoto University for her technical support to detect autoantibodies.

\section{Competing interests}

The authors declare that they have no competing interests.

\section{Availability of data and materials}

All available information is included within the manuscript.

Ethics approval and consent to participate

Not applicable.

\section{Consent to publish}

Written informed consent was obtained from the patient for publication of this case report and any accompanying images.

\section{Funding}

The authors declare that no funding was received for the publication of this case report.

\section{Publisher's Note}

Springer Nature remains neutral with regard to jurisdictional claims in published maps and institutional affiliations.

Received: 27 July 2017 Accepted: 9 January 2018

Published online: 16 January 2018

\section{References}

1. Mukae H, Ishimoto H, Sakamoto N, Hara S, Kakugawa T, Nakayama S, Ishimatsu Y, Kawakami A, Eguchi K, Kohno S. Clinical differences between interstitial lung disease associated with clinically amyopathic dermatomyositis and classic dermatomyositis. Chest. 2009;136(5):1341-7.
2. Ikeda S, Arita M, Misaki K, Mishima S, Takaiwa T, Nishiyama A, Ito A, Furuta $\mathrm{K}$, Yokoyama T, Tokioka F, et al. Incidence and impact of interstitial lung disease and malignancy in patients with polymyositis, dermatomyositis, and clinically amyopathic dermatomyositis: a retrospective cohort study. Springerplus. 2015;4:240

3. Kotani T, Makino S, Takeuchi T, Kagitani M, Shoda T, Hata A, Tabushi Y, Hanafusa T. Early intervention with corticosteroids and cyclosporin A and 2-h post dose blood concentration monitoring improves the prognosis of acute/subacute interstitial pneumonia in dermatomyositis. J Rheumatol. 2008;35(2):254-9.

4. Nagata K, Tomii K, Nanjo S, Kubota M, Tachikawa R, Nishio M. Four cases of interstitial pneumonia associated with amyopathic dermatomyositis characterized by the anti-CADM-140 antibody. Nihon Kokyuki Gakkai Zasshi. 2011:49(1):30-6.

5. Gono T, Kawaguchi Y, Hara M, Masuda I, Katsumata Y, Shinozaki M, Ota Y, Ozeki E, Yamanaka H. Increased ferritin predicts development and severity of acute interstitial lung disease as a complication of dermatomyositis, Rheumatology (Oxford). 2010:49(7):1354-60.

6. Tazelaar HD, Viggiano RW, Pickersgill J, Colby TV. Interstitial lung disease in polymyositis and dermatomyositis. Clinical features and prognosis as correlated with histologic findings. Am Rev Respir Dis. 1990;141(3):727-33.

7. Rosenschein U, Radnay J, Shoham D, Shainberg A, Klajman A, Rozenszajn LA. Human muscle-derived, tissue specific, myocytotoxic T cell lines in dermatomyositis. Clin Exp Immunol. 1987;67(2):309-18.

8. Goebels N, Michaelis D, Engelhardt M, Huber S, Bender A, Pongratz D, Johnson MA, Wekerle H, Tschopp J, Jenne D, et al. Differential expression of perforin in muscle-infiltrating $T$ cells in polymyositis and dermatomyositis. J Clin Invest. 1996;97(12):2905-10.

9. Dumont FJ. FK506, an immunosuppressant targeting calcineurin function. Curr Med Chem. 2000;7(7):731-48.

10. Webster A, Woodroffe RC, Taylor RS, Chapman JR, Craig JC. Tacrolimus versus cyclosporin as primary immunosuppression for kidney transplant recipients. Cochrane Database Syst Rev. 2005;4:CD003961.

11. Krämer BK, Montagnino G, Del Castillo D, Margreiter R, Sperschneider $\mathrm{H}$, Olbricht CJ, Krüger B, Ortuño J, Köhler H, Kunzendorf U, et al. Efficacy and safety of tacrolimus compared with cyclosporin A microemulsion in renal transplantation: 2 year follow-up results. Nephrol Dial Transplant. 2005;20(5):968-73.

12. McAlister VC, Haddad E, Renouf E, Malthaner RA, Kjaer MS, Gluud LL. Cyclosporin versus tacrolimus as primary immunosuppressant after liver transplantation: a meta-analysis. Am J Transplant. 2006;6(7):1578-85.

13. Nash RA, Antin JH, Karanes C, Fay JW, Avalos BR, Yeager AM, Przepiorka D, Davies S, Petersen FB, Bartels P, et al. Phase 3 study comparing methotrexate and tacrolimus with methotrexate and cyclosporine for prophylaxis of acute graft-versus-host disease after marrow transplantation from unrelated donors. Blood. 2000;96(6):2062-8.

14. Kameda H, Nagasawa H, Ogawa H, Sekiguchi N, Takei H, Tokuhira M, Amano K, Takeuchi T. Combination therapy with corticosteroids, cyclosporin A, and intravenous pulse cyclophosphamide for acute/subacute interstitial pneumonia in patients with dermatomyositis. J Rheumatol. 2005:32(9):1719-26.

15. Nakashima R, Imura Y, Kobayashi S, Yukawa N, Yoshifuji H, Nojima T, Kawabata D, Ohmura K, Usui T, Fujii T, et al. The RIG-I-like receptor IFIH1/ MDA5 is a dermatomyositis-specific autoantigen identified by the antiCADM-140 antibody. Rheumatology (Oxford). 2010;49(3):433-40. 